\title{
Nonlinear Feedback Linearization Control for Wind Generators in Hybrid Wind Energy Conversion Systems
}

\author{
HOA MINH NGUYEN* \\ *Department of Electrical and Electronics Engineering, \\ Tra Vinh University \\ 126 Nguyen Thien Thanh, Tra Vinh city, Tra Vinh Province \\ VIETNAM
}

\begin{abstract}
This paper deals with the optimal power extraction of wind generators in hybrid wind energy conversion systems. The proposed control technique is the nonlinear exact feedback linearization which is able to give satisfactory performances over a broad spectrum of operating points. The main contribution of the paper is the successful dealing with the most challenging task in the design of nonlinear feedback linearization controllers for wind energy conversion systems, which is the transform and manipulation of state-dependent high-order nonlinear power coefficients presented in wind turbines. In other words, this paper addresses the full-order highly nonlinear power coefficients functions instead of using approximated low-order functions as in previous works in literature. The obtained nonlinear controller is able to cope with the time-varying nature of wind turbines and maintain the optimal power conversion points. Moreover the nonlinear feedback linearization control performance is also compared to that of traditional perturbation and observation based maximum power point tracking and classical PI control. The numerical simulation outcomes show that the proposed nonlinear controller outperform those two traditional controllers in terms of maximum gained power and transient specifications.
\end{abstract}

Key-Words: - Hybrid wind energy conversion systems (HWECS); Direct drive wind turbines; Permanentmagnet synchronous generators (PMSG); Nonlinear feedback linearization control (NFLC); Proportional Integral (PI) control; Maximum power point tracking (MPPT).

Received: February 22, 2021. Revised: August 17, 2021. Accepted: September 5, 2021. Published: September 16, 2021.

\section{Introduction}

Renewable energy has been considered an inevitable alternative to fossil fuel energy sources. One of the tangible renewable energy which has been paid tremendous attention in terms of research, technology development, and commercialization is wind energy [1].

The exploitation of wind energy is mostly carried out in the form of large-scale wind turbines which are connected to power systems [2]. However standalone wind turbines, in particular in hybrid wind energy conversion systems (HWECS) still play important roles for the power supply of local or islanded areas [3].

There are two main problems from the control view points in HWECS. The first one is the power harvesting maximization of individual generating modules. The other is the power flow coordination between supply and demand sides. Of above two control problems, the first one has been attracting much attention from research communities. Various control schemes have been introduced to the maximum power point tracking (MPPT) problem of standalone wind energy conversion systems. Traditionally, MPPT algorithms are relied on the perturbation and observation principle which requires little information [4]. The primary drawback of MPPT control scheme is the possibility of misleading to optimal power points. There have been numerous techniques being proposed to compensate for the conventional MPPT control, including variable step size MPPT [5], adaptive MPPT [6], etc. Nevertheless, WECS are timevarying and highly nonlinear systems. It is therefore required to obtain much better control strategies [7]. Gain scheduling control which is suited to the timevarying nature of WECS has been proposed in [8]. Other classical linear control approaches including PI, LQR, LQG, QFT, MRAC have been tested in [9], [10], [11]. Additionally, nonlinear control approaches including sliding mode control and nonlinear model predictive control have also been designed and validated in [12], [13]. Another nonlinear control framework, the nonlinear feedback linearization control (NFLC), has also been received interests from WECS control investigators. This 
method, unlike the classical linearized approach which is based on the Taylor approximation, is able to cancel out nonlinearities in systems by the exact feedback linearization. There are few typical articles reporting the use of NFLC for wind turbines. Farshad Golnary and Hamed Moradi in [14] have designed and compared the feedback linearization control with the sliding mode control for a $1.5 \mathrm{MW}$ wind turbine. The study results indicate that the NFLC gives a slightly better performance than the sliding mode control with respect to the power extraction and load mitigation. The work in [9] presents a NFLC for a standalone PMSG-Based WECS, which demonstrates a promising optimal power points tracking under changing wind conditions. A NFLC design framework has been also proposed to doubly-fed induction generator (DFIG) based variable speed wind turbines [15]. The proposed NFLC control deals the multi-inputs, multi-outputs (MIMO) wind turbine systems. However, the most difficult step in the design of NFLC for WECS is the handle of highly nonlinear power coefficient terms. This issue has been either avoided by imposing control laws on the electromagnetic torque or using low-order approximations of power coefficients in the same previous works. Consequently, it is required to either implement another control loop for the generator torque control or limit WECS to narrower optimal operating regions.

In this paper, a NFLC scheme is synthesized for a standalone wind generator in hybrid wind energy conversion systems. The control purpose is to track the optimal tip-speed ratio and the optimal power coefficient of the wind turbines so that the power converted from wind is maximized as wind changes. The proposed controller takes into account fullorder state-dependent and highly nonlinear power/torque coefficients, providing a wider range of optimal operation for WECS. The paper is structured as follows. The introduction is given in section 1 , followed by the mathematical modeling in section 2. Section 3 describes the nonlinear feedback control design for standalone WECS. Section 4 presents the simulation results and discussion. Finally, the emphasis and conclusion are given in section 5 .

\section{System Mathematical Modeling}

\subsection{Hybrid Wind Energy Conversion Systems}

Hybrid wind energy conversion systems consist of a variety of different generating modules commonly including wind, photovoltaic (PV), Biomass, Diesel etc. A typical HWECS is shown in Fig. 1.

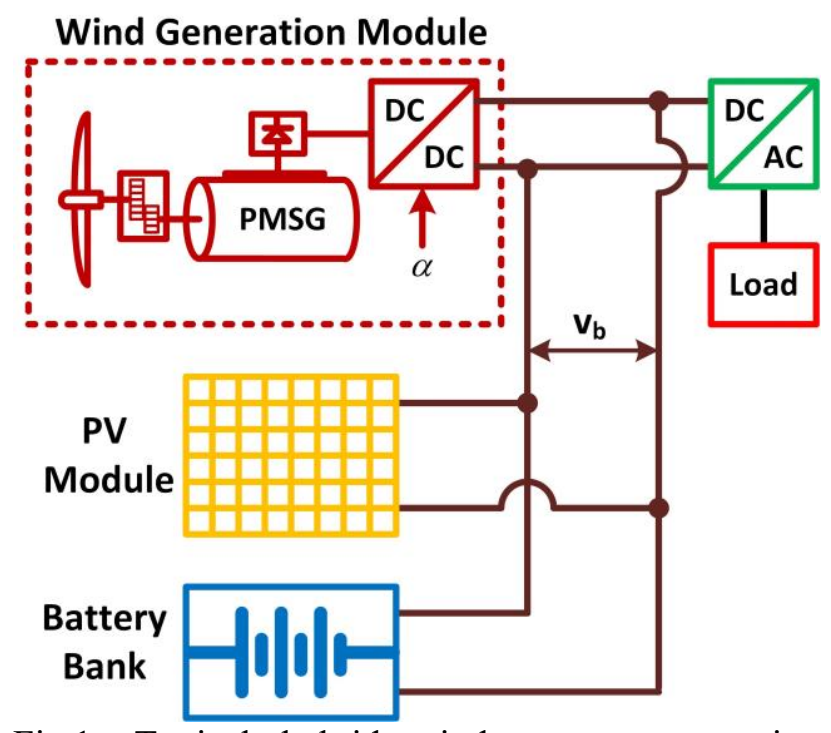

Fig.1: Typical hybrid wind energy conversion systems

The system may include one or multiple same sources of generating modules depending on the design purposes. Different energy generators are all connected to the same DC bus. Battery banks are also linked to the DC bus for the purpose of energy compensation. Inverters are used for AC loads.

\subsection{Modeling of Wind Generating Modules}

A wind generating module is generally comprised of a wind turbine, a gearbox, a generator, and a power electronic converter. However, the gearbox functioning as a speed amplifier is costly and demands regularly maintenance. As a result, gearboxes are commonly removed in direct drive wind turbines which are directly connected to electric generators. In this paper, a direct drive wind turbine with a multipoles permanent magnet generator is investigated. The generator terminal voltages are fed through a rectifier and controlled by a DC-DC converter (chopper).

The torque and power of the wind turbine are given as:

$T_{r}=\frac{1}{2} \rho \pi R^{3} v^{2} C_{Q}(\lambda, \beta)$, 
$P_{r}=\frac{1}{2} \rho \pi R^{2} v^{3} C_{Q}(\lambda, \beta) \lambda$,

or

$$
P_{r}=\frac{1}{2} \rho \pi R^{2} v^{3} C_{P}(\lambda, \beta),
$$

where $T_{r}$ and $P_{r}$ are respectively torque and power of the wind turbine; $R$ is the radius of wind rotor's swept area; $\rho$ is air density; $v$ is wind speed; $C_{Q}(\lambda, \beta)$ and $C_{P}(\lambda, \beta)$ are respectively torque and power coefficients which are highly nonlinear functions of $\lambda$ (tip-speed ratio) and $\beta$ (pitch angle). The tip-speed ratio is defined by

$\lambda=\frac{\omega_{g} R}{v}$,

where $\omega_{g}$ is the angular speed of wind turbine and generator. As indicated in (2) or (3), the power conversion is maximized as $C_{Q}(\lambda, \beta)$ or $C_{P}(\lambda, \beta)$ reach the maximum points at the optimal tip-speed ratio and pitch angle as shown in Fig. 2 and 3.

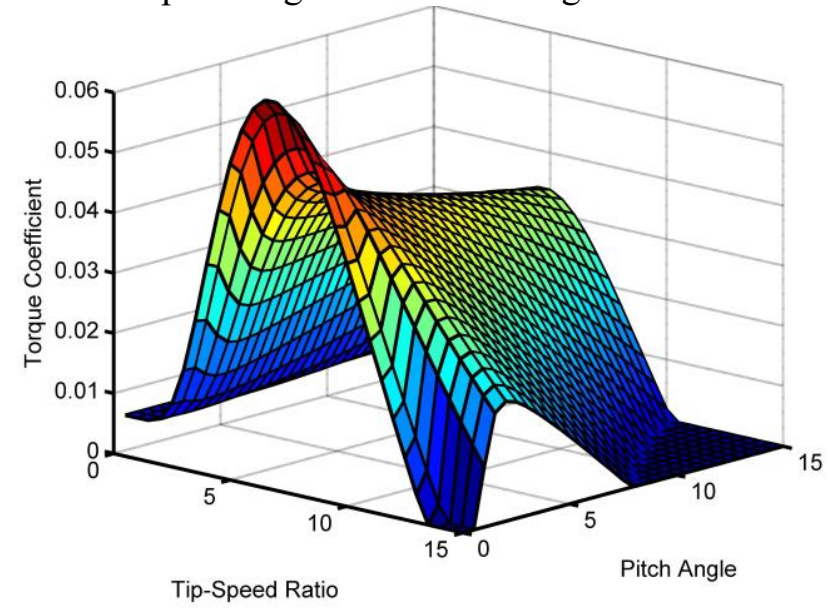

Fig. 2. Torque coefficient function

Generally the pitch angle is activated at the power regulation mode and inactive (set to zero) at the MPPT mode. Since this paper deals with the MPPT mode, $C_{Q}$ only remains a function of the tipspeed ratio and expressed as sixth-order polynomial [9]:

$$
\begin{gathered}
C_{Q}(\lambda)=a_{6} \lambda^{6}+a_{5} \lambda^{5}+a_{4} \lambda^{4}+a_{3} \lambda^{3}+a_{2} \lambda^{2} \\
+a_{1} \lambda+a_{0} .
\end{gathered}
$$

It should be noted that the torque function is highly nonlinear and hard to handle in the control design process. In this paper the power coefficient has the maximum at the optimal $\lambda^{*}$.

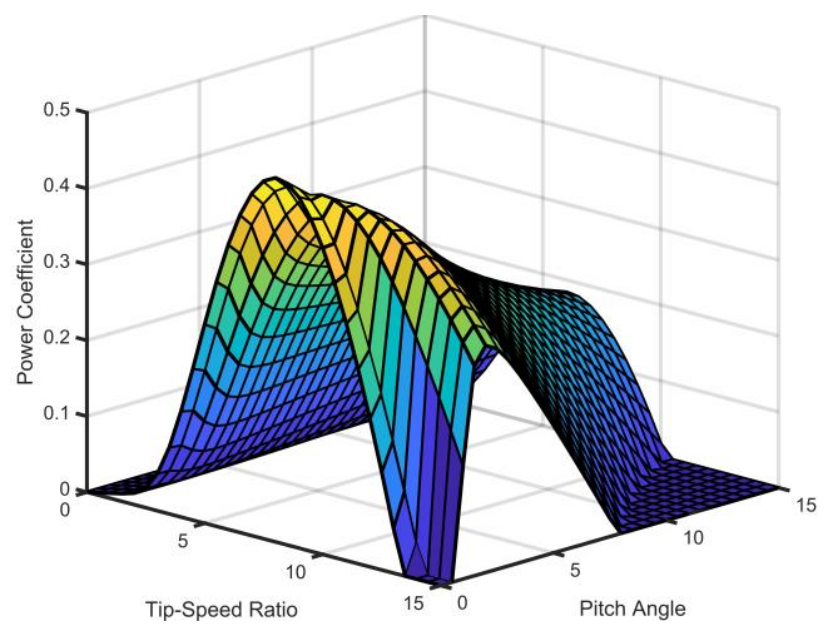

Fig. 3. Power coefficient function

The PMSG dynamical model in the $\mathrm{d}-\mathrm{q}$ coordinate is given as following [16]:

$\dot{i_{q}}=\frac{1}{L_{s}}\left(-R_{s} i_{q}-\omega_{g} L_{s} i_{d}+\omega_{g} \phi_{m}-u_{q}\right)$

$\dot{i_{d}}=\frac{1}{L_{s}}\left(-R_{s} i_{d}+\omega_{g} L_{s} i_{q}-u_{d}\right)$

$\dot{\omega}_{g}=\frac{p}{2 J}\left(T_{r}-T_{g}\right)$

where $i_{q}, i_{d}$ are the quadrature and direct stator currents; $\omega_{g}$ is the generator rotational speed; $L_{s}$ is the generator inductance; $R_{S}$ is the generator resistance; $\phi_{m}$ is the linked flux; $p$ is the pole number; $J$ is the total inertia rendered to the generator side; $u_{q}, u_{d}$ are the quadrature and direct voltages; $T_{r}$ and $T_{g}$ are the wind turbine and generator torque respectively. The generator torque relation is given as

$T_{g}=\frac{3 p}{4} \phi_{m} i_{q}$.

The PMSG terminal voltages can be regulated by adjusting the duty cycle, $\alpha$, of the DC-DC converter. If the rectifier is given in half-bridge topology, the relation between the voltage of DC bus $\left(v_{b}\right)$ and the PMSG voltage $\left(V_{S}\right)$ is given as

$V_{s}=\frac{\pi v_{b}}{3 \sqrt{3}} u$.

where $u=K_{w} / \alpha$ is the control signal. $K_{w}$ is the transformer winding ratio. By expressing the voltage $V_{S}$ in the d-q rotor coordinate, the dynamical model (5)-(7) become 


$$
\begin{array}{r}
\dot{i_{q}=\frac{-R_{s} i_{q}}{L_{s}}-\omega_{g} i_{d}+\frac{\omega_{g} \phi_{m}}{L_{s}}} \\
-\frac{\pi v_{b} i_{q} u}{3 \sqrt{3} L_{s} \sqrt{i_{q}^{2}+i_{d}^{2}}}
\end{array}
$$$$
\dot{i_{d}}=\frac{-R_{s} i_{d}}{L_{s}}+\omega_{g} i_{q}-\frac{\pi v_{b} i_{d} u}{3 \sqrt{3} L_{s} \sqrt{i_{q}^{2}+i_{d}^{2}}}
$$$$
\dot{\omega}_{g}=\frac{p}{2 J}\left(\frac{1}{2} \rho \pi R^{3} v^{2} C_{Q}(\lambda)-\frac{3 p}{4} \phi_{m} i_{q}\right)
$$

The total PMSG current supplied to the DC bus can be described as

$$
i_{g}=\frac{\pi u}{2 \sqrt{3}} \sqrt{i_{q}^{2}+i_{d}^{2}}
$$

\section{Control Design Scheme}

\subsection{Nonlinear Feedback Linearization Control}

Unlike classical control techniques which are based on the approximation linearization methods, and hence only give good control performances in the vicinity of each operating point, the feedback linearization control, which fully eradicates the nonlinearity, is able to perform over a large domain of operating points. In this study, an input-output feedback linearization which linearizing the inputoutput relationship is employed. This control scheme can be shortly described as following.

Take a nonlinear single input-single output system:

$\dot{x}=f(x)+g(x) u$

$y=h(x)$

where $x \in R^{n}$ is the state vector; $y$ is the system output; $u$ is the system input; $f(x), g(x), h(x)$ are nonlinear functions of the state vector $x$. Let's take the derivative of the systems output $r$ times until the system input apprears explicitly as

$y^{(r)}=L_{f}^{(r)} h(x)+L_{g} L_{f}^{(r-1)} h(x) u$ where $y^{(r)}$ is r-th order derivative of $y$ with $r$ being called the relative degree; $L_{f}^{(r)} h(x)$ and $L_{g} L_{f}^{(r-1)} h(x)$ are Lie derivatives of $h(x)$. If $L_{g} L_{f}^{(r-1)} h(x) \neq 0, u$ can be taken as

$$
u=-\frac{L_{f}^{(r)} h(x)}{L_{g} L_{f}^{(r-1)} h(x)}+\frac{1}{L_{g} L_{f}^{(r-1)} h(x)} u_{v}
$$

or

$$
u=\alpha(x)+\beta(x) u_{v}
$$

where $u_{v}$ is the linearized control input. By using the nonlinear state feedback (18) and the state coordinate transform $z=T(x)$, the nonlinear system can be transformed into a linear system as

$\dot{z}=A z+B u_{v}$

It is remarked that classical linear control techniques such as pole placement can be used for the control design of the resultant linear system (19).

\subsection{Design of Feedback Linearization Controller}

The feedback linearization control scheme described above is applied for the design of the maximum power point tracking controller. The control purpose is to track the rotational optimal reference speed (20) when the wind speed changes. $\omega_{g}^{r}=\frac{\lambda^{*} v}{R}$

The nonlinear dynamical model the PMSGBased WECS from (10)-(12) is the subject to the NLFC synthesis. For the simplicity, let's assign following notations: $d_{1}=-R_{s} / L_{s}, d_{2}=\phi_{m} / L_{s}$, $d_{3}=-\pi v_{b} / 3 \sqrt{3} L_{s}, \quad d_{4}=p \rho \pi R^{3} / 4 J, \quad d_{5}=$ $3 p^{2} \phi_{m} / 8 \mathrm{~J}$. The equation (12) can be rewritten as

$\dot{\omega}_{g}=d_{4} C_{Q}(\lambda) v^{2}-d_{5} i_{q}$

Substituting (3) into (21), the $d_{4} C_{Q}(\lambda) v^{2}$ will become 


$$
\begin{aligned}
d_{4} C_{Q}(\lambda) v^{2}= & d_{4} v^{2}\left[a_{0}+a_{1}\left(\frac{\omega_{g} R}{v}\right)+a_{2}\left(\frac{\omega_{g} R}{v}\right)^{2}\right. \\
& +a_{3}\left(\frac{\omega_{g} R}{v}\right)^{3}+a_{4}\left(\frac{\omega_{g} R}{v}\right)^{4} \\
& \left.+a_{5}\left(\frac{\omega_{g} R}{v}\right)^{5}+a_{6}\left(\frac{\omega_{g} R}{v}\right)^{6}\right]
\end{aligned}
$$

or

$$
\begin{aligned}
d_{4} C_{Q}(\lambda) v^{2}= & d_{6} v^{2}+d_{7} v \omega_{g}+d_{8} \omega_{g}^{2}+d_{9} \frac{\omega_{g}^{3}}{v} \\
& +d_{10} \frac{\omega_{g}^{4}}{v^{2}}+d_{11} \frac{\omega_{g}^{5}}{v^{3}}+d_{12} \frac{\omega_{g}^{6}}{v^{4}}
\end{aligned}
$$

where $d_{6}=d_{6} a_{0}, \quad d_{7}=d_{4} a_{1} R, \quad d_{8}=d_{4} a_{2} R^{2}$, $d_{9}=d_{4} a_{3} R^{3}, \quad d_{10}=d_{4} a_{4} R^{4}, \quad d_{11}=d_{4} a_{5} R^{5}$, $d_{12}=d_{4} a_{6} R^{6}$.

Define the state vector $x^{T}=\left[\begin{array}{lll}x_{1} & x_{2} & x_{3}\end{array}\right]^{T}=$ $\left[\begin{array}{lll}i_{q} & i_{d} & \omega_{g}\end{array}\right]^{T}$ and the system output is $\omega_{g}$, the PMSGBased nonlinear can be rewritten as

$$
\begin{aligned}
& \dot{x}_{1}=d_{1} x_{1}-x_{2} x_{3}+d_{2} x_{3}+\frac{d_{3} x_{1} u}{\sqrt{x_{1}^{2}+x_{2}^{2}}} \\
& \dot{x}_{2}=d_{1} x_{2}+x_{1} x_{3}+\frac{d_{3} x_{2} u}{\sqrt{x_{1}^{2}+x_{2}^{2}}}
\end{aligned}
$$

$$
\begin{gathered}
\dot{x}_{3}=d_{6} v^{2}+d_{7} v x_{3}+d_{8} x_{3}^{2}+d_{9} \frac{x_{3}^{3}}{v}+d_{10} \frac{x_{3}^{4}}{v^{2}} \\
+d_{11} \frac{x_{3}^{5}}{v^{3}}+d_{12} \frac{x_{3}^{6}}{v^{4}}-d_{5} x_{1}
\end{gathered}
$$

$y=x_{3}$

It is straightforward to calculate and obtain the relative degree of the nonlinear system (24)-(27) is $r=2$. According to [17], a state coordinate transform that brings the system into the normal form and meets the diffeomorphism condition is defined by

$$
z=T(x)=\left[\begin{array}{c}
h(x) \\
L_{f} h(x) \\
\mu(x)
\end{array}\right]
$$

where $\quad h(x)=x_{3}, \quad L_{f} h(x)=\frac{\partial h(x)}{\partial x} f(x)=f_{3}(x)$ (the right hand side terms of (26)), $\mu(x)$ is a function of $x$. This function must be fulfilled with the condition

$\frac{\partial \mu(x)}{\partial x} g(x)=0$ which can be expanded as $\frac{\partial \mu(x)}{\partial x_{1}} g_{1}(x)+\frac{\partial \mu(x)}{\partial x_{2}} g_{2}(x)+\frac{\partial \mu(x)}{\partial x_{3}} g_{3}(x)=0$

or

$\frac{\partial \mu(x)}{\partial x_{1}} \frac{d_{3} x_{1}}{\sqrt{x_{1}^{2}+x_{2}^{2}}}+\frac{\partial \mu(x)}{\partial x_{2}} \frac{d_{3} x_{2}}{\sqrt{x_{1}^{2}+x_{2}^{2}}}=0$

It is not difficult to choose $\mu(x)=d_{3} x_{1} / x_{2}$ that satisfies the above equation (29). As a result, the state coordinate transform obtained as

$z_{1}=x_{3}$

$z_{2}=d_{6} v^{2}+d_{7} v x_{3}+d_{8} x_{3}^{2}+d_{9} \frac{x_{3}^{3}}{v}+d_{10} \frac{x_{3}^{4}}{v^{2}}$ $+d_{11} \frac{x_{3}^{5}}{v^{3}}+d_{12} \frac{x_{3}^{6}}{v^{4}}-d_{5} x_{1}$

$z_{3}=\frac{d_{3} x_{1}}{x_{2}}$

The inverse state coordinate transform is found as

$$
\begin{gathered}
x_{1}=\frac{1}{d_{5}}\left(d_{6} v^{2}+d_{7} v z_{1}+d_{8} z_{1}^{2}+\frac{d_{9} z_{1}^{3}}{v}+\frac{d_{10} z_{1}^{4}}{v^{2}}\right. \\
\left.+\frac{d_{11} z_{1}^{5}}{v^{3}}+\frac{d_{12} z_{1}^{6}}{v^{4}}-z_{2}\right) \\
x_{2}=\frac{d_{3}}{d_{5} z_{3}}\left(d_{6} v^{2}+d_{7} v z_{1}+d_{8} z_{1}^{2}+\frac{d_{9} z_{1}^{3}}{v}+\frac{d_{10} z_{1}^{4}}{v^{2}}\right. \\
+ \\
\left.+\frac{d_{11} z_{1}^{5}}{v^{3}}+\frac{d_{12} z_{1}^{6}}{v^{4}}-z_{2}\right)
\end{gathered}
$$

$z_{3}=x_{1}$

Since the relative degree is $r=2$, the state feedback control is expressed by

$u=\frac{-L_{f}^{2} h(x)+u_{v}}{L_{g} L_{f} h(x)}$

It is simple to calculate Lie derivatives from (26) as

$L_{f}^{2} h(x)=-d_{5} f_{1}(x)+F(x) f_{3}(x)$

$L_{g} L_{f} h(x)=-d_{5} g_{1}(x)=\frac{-d_{5} d_{3} x_{1}}{\sqrt{x_{1}^{2}+x_{2}^{2}}}$

where

$$
\begin{aligned}
& f_{1}(x)=d_{1} x_{1}-x_{2} x_{3}+d_{2} x_{3} \\
& f_{3}(x)=d_{6} v^{2}+d_{7} v x_{3}+d_{8} x_{3}^{2}+d_{9} \frac{x_{3}^{3}}{v}+d_{10} \frac{x_{3}^{4}}{v^{2}} \\
& \quad+d_{11} \frac{x_{3}^{5}}{v^{3}}+d_{12} \frac{x_{3}^{6}}{v^{4}}-d_{5} x_{1}
\end{aligned}
$$




$$
\begin{gathered}
F(x)=d_{7} v+2 d_{8} x_{3}+\frac{3 d_{9} x_{3}^{2}}{v}+\frac{4 d_{10} x_{3}^{3}}{v^{2}}+\frac{5 d_{11} x_{3}^{4}}{v^{3}} \\
+\frac{6 d_{12} x_{3}^{5}}{v^{4}}
\end{gathered}
$$

After using the state feedback control (36) the linear system is produced as

$$
\begin{aligned}
& {\left[\begin{array}{l}
\dot{z}_{1} \\
\dot{z}_{2}
\end{array}\right]=\left[\begin{array}{ll}
0 & 1 \\
0 & 0
\end{array}\right]\left[\begin{array}{l}
z_{1} \\
z_{2}
\end{array}\right]+\left[\begin{array}{l}
0 \\
1
\end{array}\right] u_{v}} \\
& y=\left[\begin{array}{ll}
1 & 0
\end{array}\right]\left[\begin{array}{l}
z_{1} \\
z_{2}
\end{array}\right]
\end{aligned}
$$

In order to decrease the tracking error, an integer block is inserted into the linear control scheme as shown in Fig. 4.

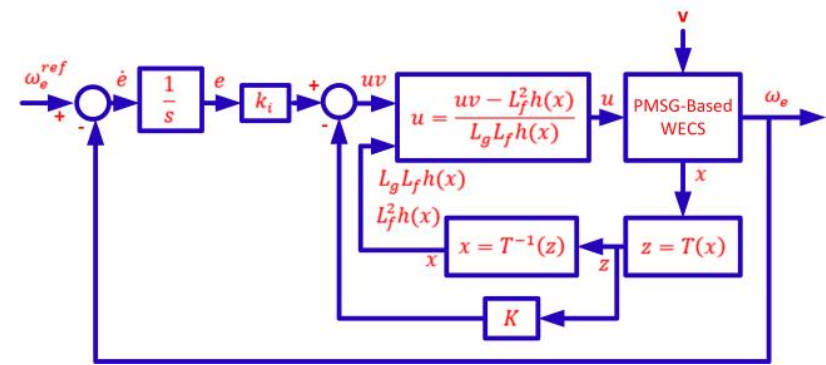

Fig. 4: Input-Output feedback linearization control diagram

As a result, the linear control becomes

$u_{v}=K z+k_{i} e=\left[\begin{array}{ll}k_{1} & k_{2}\end{array}\right]\left[\begin{array}{l}Z_{1} \\ z_{2}\end{array}\right]+k_{i} e$

where

$$
\dot{e}=\omega_{e}^{r e f}-\omega_{e}=\omega_{e}^{r e f}-\left[\begin{array}{ll}
1 & 0
\end{array}\right]\left[\begin{array}{l}
Z_{1} \\
z_{2}
\end{array}\right]
$$

Therefore, the augmented linear system is yielded as

$\left[\begin{array}{c}\dot{z}_{1} \\ \dot{z}_{2} \\ \dot{e}\end{array}\right]=\left[\begin{array}{ccc}0 & 1 & 0 \\ 0 & 0 & 0 \\ -1 & 0 & 0\end{array}\right]\left[\begin{array}{c}z_{1} \\ z_{2} \\ e\end{array}\right]+\left[\begin{array}{l}0 \\ 1 \\ 0\end{array}\right] u_{v}+\left[\begin{array}{l}0 \\ 0 \\ 1\end{array}\right] \omega_{e}^{r e f}$

The linear control law computed by the pole placement technique is given by

$u_{v}=-\left[\begin{array}{lll}k_{1} & k_{2} & -k_{i}\end{array}\right]\left[\begin{array}{c}z_{1} \\ z_{2} \\ e\end{array}\right]$

\section{Simulation and Discussion}

The above nonlinear feedback linearization control design and the PMSG-Based wind generator are both realized and simulated in the MATLAB/SIMULINK environments. The simulation parameters are given as: $\rho=$ $1.25 \mathrm{~kg} / \mathrm{m}^{3}, \quad R=1.84 \mathrm{~m}, J=7.856 \mathrm{~kg} . \mathrm{m}^{2}$, $L_{s}=3.55 \mathrm{mH}, p=28, R_{s}=0.3676 \Omega, \phi_{m}=$ $0.2867 \mathrm{~Wb}, \quad a_{0}=0.0061, \quad a_{1}=0.0013$, $a_{2}=0.0081, \quad a_{3}=-9.7477 \times 10^{-4}, \quad a_{4}=$ $-6.5416 \times 10^{-5}, a_{5}=1.3027 \times 10^{-5}, a_{6}=$
$-4.54 \times 10^{-7}, \quad \lambda^{*}=7, \quad C_{p_{\max }}=0.47 . \quad$ The simulation time is $100 \mathrm{sec}$.

The linear controller's parameters in (48) are designed by the pole assignment approach. The desire poles are calculated with cut-off frequency $\omega_{n}=20 \mathrm{rad} / \mathrm{s}$ and the damping coefficient $\xi=$ 0.7. The obtained parameters are $k_{1}=872.49$, $k_{2}=41.4, k_{i}=32660$. The simulated wind speed demonstrated in Fig. 5 varied from 7-9 m/s. The average wind speed is $9 \mathrm{~m} / \mathrm{s}$ and the turbulence intensity is $I=0.15$ using the Von Karman spectrum according to the IEC standard.

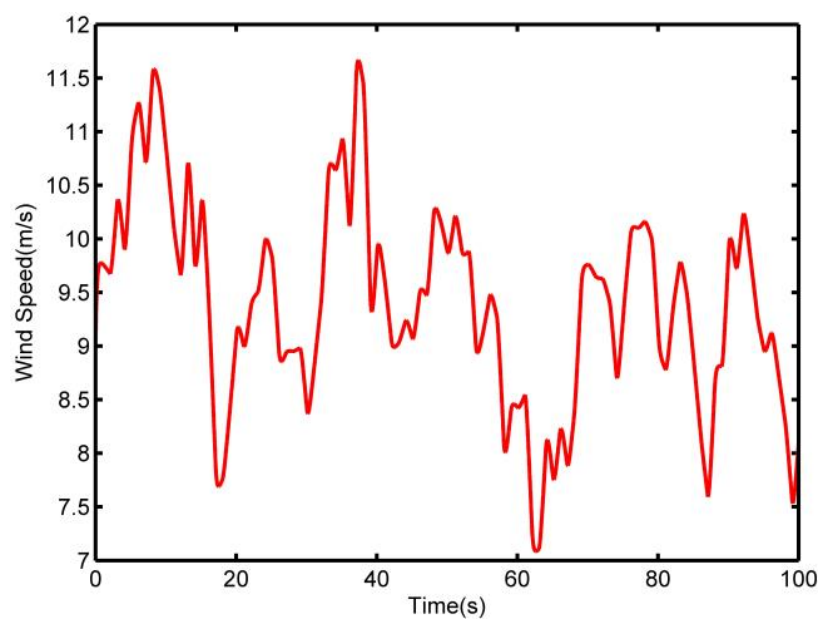

Fig.5: The variable wind speed for simulation

Fig. 6 shows the output reference tracking comparison among three control approaches including PI, NFLC, MPPT (P\&O-Based). It is observed that the PI and NFLC have better reference tracking performance compared to the MPPT control.

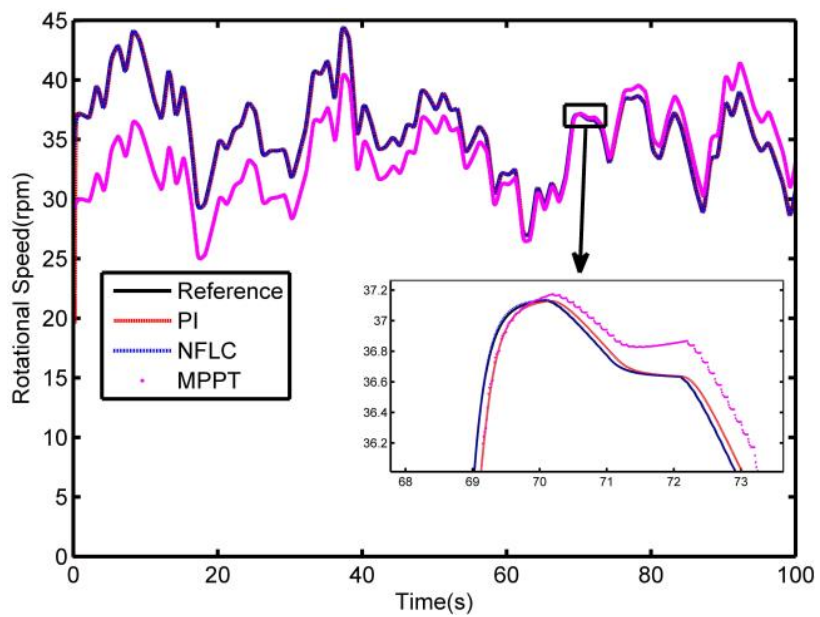

Fig.6: Output tracking performance 


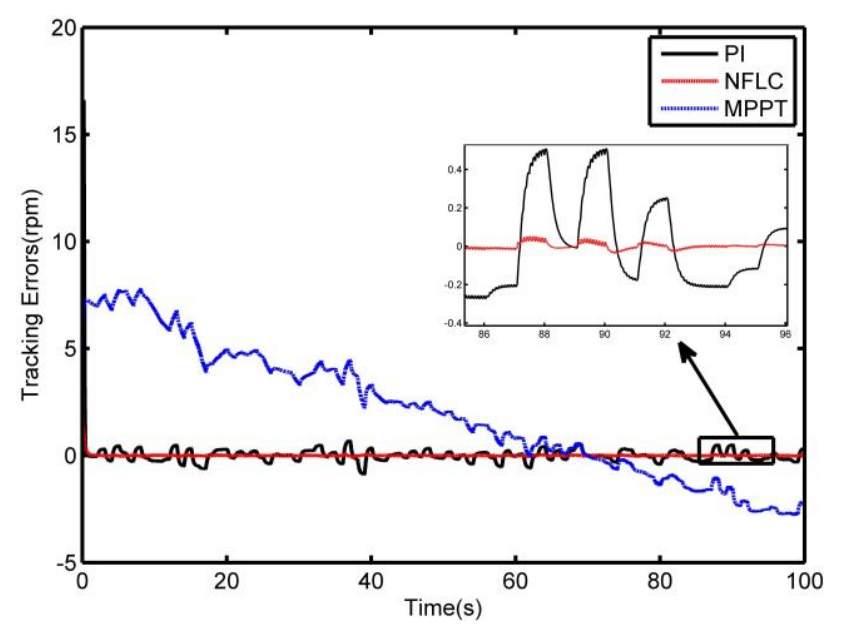

Fig.7: Output tracking errors

Fig. 7 gives a clearer demonstration between PI and NFLC tracking performance. The PI tracking error is fluctuating around the zero axis whereas the NFLC one is quite steady at the mean value. The tracking error performance with respect to the statistical aspect is displayed in Table 1.

Table 1. Mean and standard deviations of tracking errors

\begin{tabular}{|c|c|c|}
\hline Controller & Mean & Standard deviation \\
\hline NFLC & 0.017 & 1.04 \\
\hline PI & 0.25 & 1.68 \\
\hline MPPT & 3.43 & 3.01 \\
\hline
\end{tabular}

Fig. 8 depicts optimal power conversion status by showing how well the maximum power gained. Again, the PI and NFLC show better maximum power coefficient maintenance compared to the MPPT. Fig. 8 also indicates that the NFLC is slightly better than PI in keeping the maximum power coefficient.

Another indication of the optimal power capture is the optimal regimes characteristic (ORC) which is a line going through maxima corresponding to each wind speed. Fig. 9 illustrates the NFLC phase portrait showing the system retains at the ORC under wind speed changing situations.

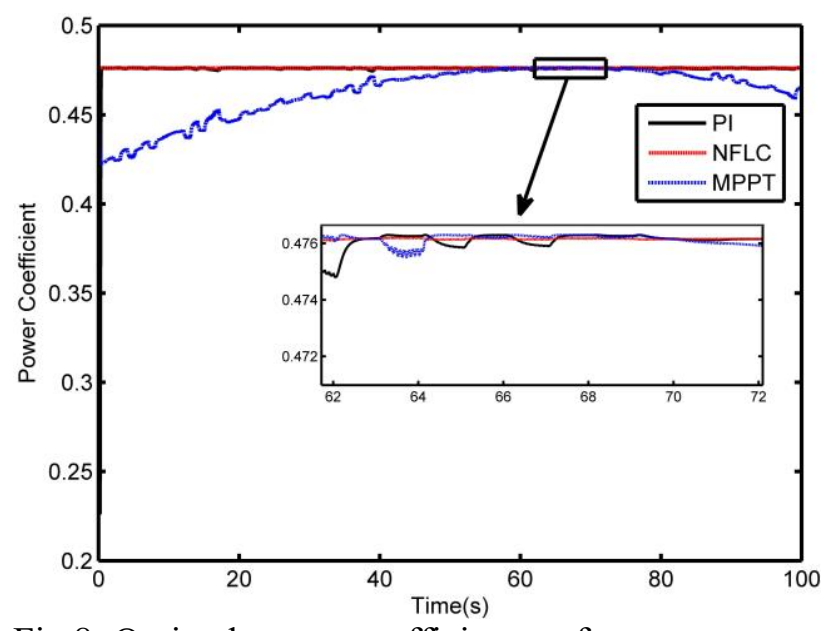

Fig.8: Optimal power coefficient performance

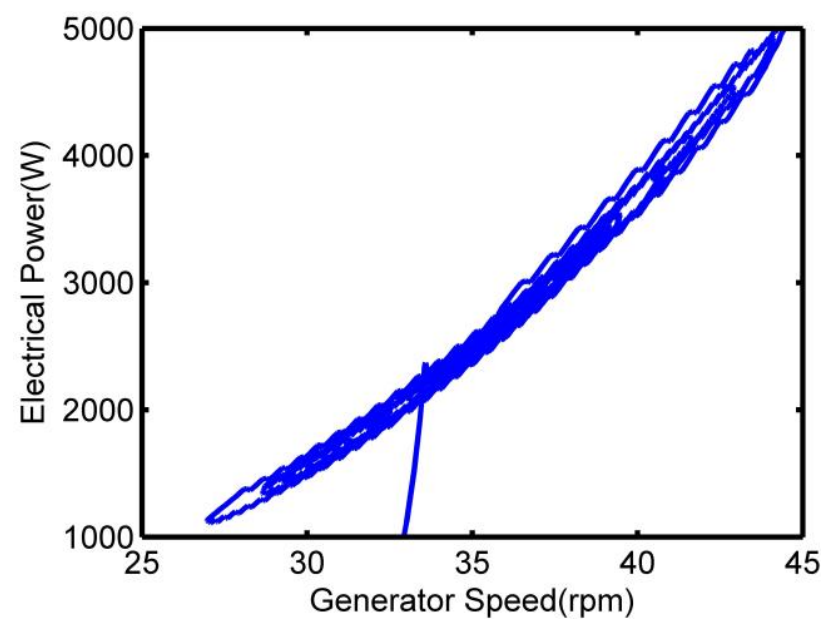

Fig.9: NFLC phase portrait

Finally the maximum electrical harvested power is shown in Fig. 10 which points that the NFLC has the largest electrical power gained.

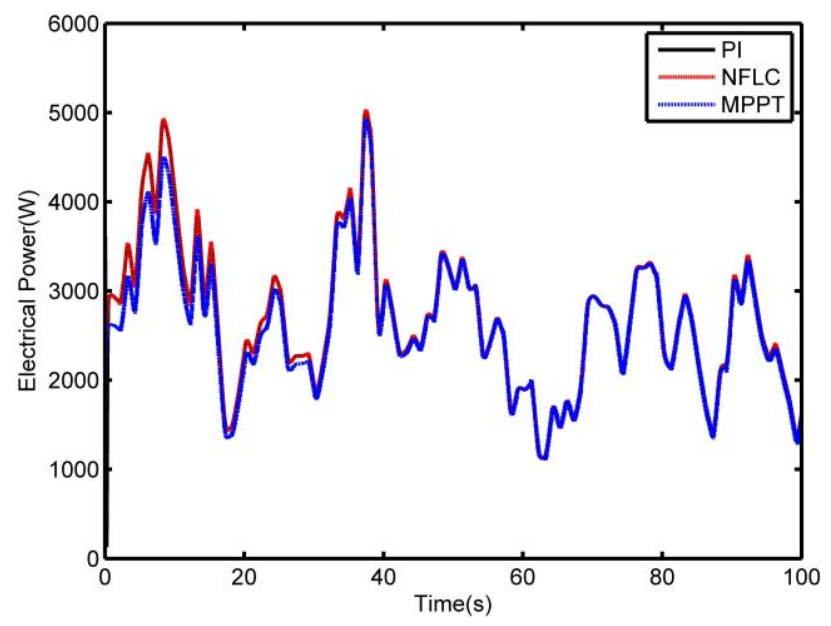

Fig.10: Comparison of generated electrical power 


\section{Conclusion}

This paper has studied the maximum power conversion of wind generators in HWECS by means of input-output feedback linearization. The control purpose is to track the optimal power coefficient and tip-speed ratio of the wind turbine; hence maximize the power captured from wind power. Unlike the same previous works which avoid or use low-order polynomials describing power coefficients, the proposed control takes into consideration the full order of power coefficient polynomials. The simulation results have indicated the superiority compared to the PI and traditional MPPT control. In particular, the proposed NFLC is totally and far better than the traditional perturb \& observe MPPT with respect to the transient and power conversion performances. The NFLC is also better than the PI control in terms of the output reference tracking error and the optimal tip-speed ratio/power coefficient maintenance. However the proposed control scheme has some limitations. First the NFLC requires full state measurements which are not always available in practice. Thus, many sensors must be used for the real time NFLC implementation. Second the NFLC is sensitive to disturbances such as unmodeled dynamics, parameter drifting, and noises. In future works, it is recommended to combine the NFLC technique with state observers for the estimation of state variables instead of using costly sensors. It would also be useful to design uncertainty accommodation methods for the NFLC framework for next studies.

\section{References:}

[1] T. Ackermann, Wind Power in Power Systems, John Wiley \& Sons, 2005.

[2] B. Fox, D. Flynn, L. Bryans, N. Jenkins, D. Milborrow, M. O'Malley, R. Watson and O. Anaya-Lara, Wind Power Integration Connection and system operational aspects, London: The Institution of Engineering and Technology, 2007.

[3] J. K. Kaldellis, Stand-alone and hybrid wind energy systems, Woodhead Publishing Limited and CRC Press LLC, 2010.

[4] H. H.H.Mousa, A.-R. Youssef and E. E. Mohamed, "State of the art perturb and observe MPPT algorithms based wind energy conversion systems: A technology review,"
International Journal of Electrical Power \& Energy Systems, vol. 126, 2021.

[5] H. H. H. Mousa, A.-R. Youssef and E. E. M. Mohamed, "Variable step size P\&O MPPT algorithm for optimal power extraction of multi-phase PMSG based wind generation system," International Journal of Electrical Power \& Energy Systems, vol. 108, pp. 218231, 2019.

[6] J. Hussain and M. K. Mishra, "Adaptive Maximum Power Point Tracking Control Algorithm for Wind Energy Conversion Systems," IEEE Transactions on Energy Conversion, vol. 31, no. 2, pp. 697 - 705, 2016.

[7] H. M. Nguyen and D. S. Naidu, "Advanced control strategies for wind energy control systems: An overview," in 2011 IEEE PES Power Systems Conference \& Exposition (PSCE), Phoenix, 2011.

[8] F. D. Bianchi, H. D. Battista and R. J. Mantz, Wind Turbine Control Systems: Principles, Modelling and Gain Scheduling Design, Springer, 2007.

[9] I. Munteanu, A. I. Bratcu, N.-A. Cutululis and E. Ceanga, Optimal Control of Wind Energy Systems: Towards a Global Approach, Springer, 2008.

[10] Y. Daili, J.-P. Gaubert, L. Rahmani and A. Harrag, "Quantitative Feedback Theory design of robust MPPT controller for Small Wind Energy Conversion Systems: Design, analysis and experimental study," Sustainable Energy Technologies and Assessments, vol. 35, pp. 308-320, 2019.

[11] M. Doumi, A. G. Aissaoui, M. Abid, I. Colak and A. Tahour, "Robust MRAC For A Wind Turbine Based On A Doubly-Fed Induction Generator," in 6th International Conference on Renewable Energy Research and Applications, San Diego, CA, USA, 2017.

[12] B. Kelkoul and A. Boumediene, "Stability analysis and study between classical sliding mode control (SMC) and super twisting algorithm (STA) for doubly fed induction generator (DFIG) under wind turbine," Energy, vol. 214, 2021.

[13] K. Ouari, T. Rekioua and M. Ouhrouche, "Real time simulation of nonlinear generalized predictive control for wind energy conversion system with nonlinear observer," ISA Transactions, vol. 53, no. 1, pp. 76-84, 2014.

[14] F. Golnary and H. Moradi, "Design and comparison of quasi continuous sliding mode control with feedback linearization for a large scale wind turbine with wind speed 
estimation," Renewable Energy, vol. 127, pp. 495-508, 2018.

[15] A. Fekih and A. A. Shehri, "A Feedback Linearization Based Nonlinear Control Approach for Variable Speed Wind Turbines," Journal of Technology Innovations in Renewable Energy, vol. 2, pp. 88-97, 2013.

[16] F. Valenciaga and P. F. Puleston, "High-Order sliding control for a wind energy conversion system based on a permanent magnet synchronous generator," IEEE Transaction on energy conversion, vol. 23, no. 3, pp. 860-867, 2008.

[17] H. J. Marquez, Nonlinear Control Systems, New Jersey, USA: John Wiley \& Sons, 2003.

[18] GodpromesseKenné, R. Goma, H. Nkwawo, F. Lamnabhi-Lagarrigue, A. Arzandé and J. C. Vannier, "An improved direct feedback linearization technique for transient stability enhancement and voltage regulation of power generators," International Journal of Electrical Power \& Energy Systems, vol. 32, no. 7, pp. 809-816, 2010.

[19] M. M. Bajestan, H. Madadi and M. A. Shamsinejad, "Control of a new stand-alone wind turbine-based variable speed permanent magnet synchronous generator using quasi-Zsource inverter," Electric Power Systems Research, vol. 177, no. 106010, 2019.

[20] I. A. d. Azevedo, L. S. Barros and C. D. Cunha, "Model reference adaptive control for squirrelcage induction generator-based wind energy conversion systems," in International Conference on Power Systems Transients (IPST), Perpignan, France, 2019.

[21] B. Babaghorbani, M. T. Beheshti and $\mathrm{H}$. AliTalebi, "A Lyapunov-based model predictive control strategy in a permanent magnet synchronous generator wind turbine," International Journal of Electrical Power \& Energy Systems, vol. 130, p. 106972, 2021.
Contribution of Individual Authors to the Creation of a Scientific Article (Ghostwriting Policy)

Hoa Minh Nguyen carried out conceptual framework; system design, analysis, simulations, discussion, writing, proofreading and editing.

\section{Sources of Funding for Research Presented in a Scientific Article or Scientific Article Itself}

This research is fully supported by Tra Vinh University.

\section{Creative Commons Attribution License 4.0 (Attribution 4.0 International, CC BY 4.0)}

This article is published under the terms of the Creative Commons Attribution License 4.0 https://creativecommons.org/licenses/by/4.0/deed.en US 